\title{
Review
}

\section{How to Prevent Aseptic Loosening in Cementless Arthroplasty: A Review}

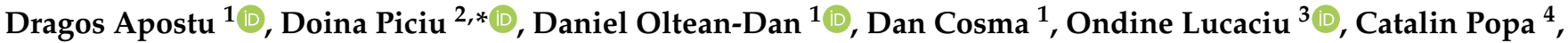 \\ Alexandru Mester ${ }^{3}$ and Horea Benea ${ }^{1}$
}

1 Department of Orthopaedics and Traumatology, University of Medicine and Pharmacy Cluj-Napoca, 400012 Cluj-Napoca, Romania; apostudragos@yahoo.com (D.A.); olteandandaniel@yahoo.com (D.O.-D.); dicosma@gmail.com (D.C.); beneahorea@yahoo.com (H.B.)

2 Nuclear Medicine Department, University of Medicine and Pharmacy Cluj-Napoca, 400012 Cluj-Napoca, Romania

3 Department of Oral Rehabilitation, University of Medicine and Pharmacy Cluj-Napoca, 400012 Cluj-Napoca, Romania; ondineluc@yahoo.com (O.L.); alexandrumester@yahoo.com (A.M.)

4 Department of Materials Science and Engineering, Technical University of Cluj-Napoca, 400641 Cluj-Napoca, Romania; catalin.popa@stm.utcluj.ro

* Correspondence: doina.piciu@gmail.com

Citation: Apostu, D.; Piciu, D.; Oltean-Dan, D.; Cosma, D.; Lucaciu, O.; Popa, C.; Mester, A.; Benea, H. How to Prevent Aseptic Loosening in Cementless Arthroplasty: A Review. Appl. Sci. 2022, 12, 1571. https:// doi.org/10.3390/app12031571

Academic Editors: Dinu Vermesan and Horia Haragus

Received: 26 December 2021

Accepted: 29 January 2022

Published: 1 February 2022

Publisher's Note: MDPI stays neutral with regard to jurisdictional claims in published maps and institutional affiliations.

Copyright: (c) 2022 by the authors. Licensee MDPI, Basel, Switzerland. This article is an open access article distributed under the terms and conditions of the Creative Commons Attribution (CC BY) license (https:// creativecommons.org/licenses/by/ $4.0 /)$.

\begin{abstract}
Aseptic loosening is the main late postoperative complication of cementless total hip arthroplasties (THAs), leading to pain and functional impairment. This article aims to update the orthopedic surgeon on the various methods by which the aseptic loosening rate can be reduced. We performed a systematic review by searching the PubMed database for hip aseptic loosening. We included meta-analysis, randomized controlled trials, reviews, and systematic reviews in the last 10 years, which provided information on techniques that can prevent aseptic loosening in total hip arthroplasty. From a total of 3205 articles identified, 69 articles (2\%) met the inclusion criteria, leading to a total of 36 recommendations. A lot of research has been conducted in terms of septic loosening in the last decade. Currently, we have various techniques by which we can reduce the rate of aseptic loosening. Nevertheless, further randomized clinical trials are needed to expand the recommendations for aseptic loosening prevention.
\end{abstract}

Keywords: aseptic loosening; total hip arthroplasty; total hip replacement; osseointegration

\section{Introduction}

Total hip arthroplasty (THA) is one of the most frequently performed orthopedic procedures worldwide, being used to treat hip osteoarthritis and hip fractures. The overall results of THAs are very good in the majority of cases, resulting in pain decrease, as well as improvement of mobility and hip function. There are two main types of THAs according to bone-implant fixation: cemented and cementless. There are still debates regarding the indications of the two methods of fixation. Generally, cemented THAs are chosen when poor bone quality is present, while cementless THAs are indicated in the case of good bone quality. Still, cementless fixation is gaining more indications in the last decade, thus becoming the most used method of fixation in the case of primary THAs. Nevertheless, there is still debate regarding the survivorship in cementless vs. cemented total hip replacements. A study on 170,413 THAs showed that cementless THAs had a higher risk of aseptic loosening compared to cemented THAs $(\mathrm{RR}=1.5)$ [1].

Complications of cementless THAs vary from mild to life-threatening ones. The most frequent late complication is represented by aseptic loosening, meaning a failure at the implant-bone interface, without the presence of infection. This complication leads to pain and functional impairment of the involved hip, severely decreasing the patient's quality of life. A key factor in preventing aseptic loosening is a good connection between the bone and the implant, a process called osseointegration. 
The treatment of aseptic loosening is generally represented by a revision total hip arthroplasty. This is a complex surgery performed in specialized centers, while the functional results are generally worse compared to a primary total hip replacement [2]. Moreover, revision surgery involves a huge cost to the healthcare system.

Researchers and clinicians are constantly trying to discover new ways to prevent this complication and therefore increase the survivorship of total hip arthroplasties. This review aims to update both clinicians and researchers on the advances in the field of aseptic loosening prevention in the last decade.

\section{Pathophysiology of Aseptic Loosening}

To prevent or treat the aseptic loosening of a cementless total hip replacement, we must first understand the pathophysiology of this process. Aseptic loosening can have different causes, that are (1) improper initial fixation, (2) mechanical loss of fixation over time, and (3) biological loss of fixation due to particle debris [3].

An improper initial fixation, or osseointegration, can have the following causes: implant properties, bone quality, surgical technique, host's healing process, and loading conditions [4]. The main cause of aseptic loosening is represented by wear debris from the implant's bearing surface, which further initiates an inflammatory response from the host's immune system [5]. This effect increases the bone resorption activity of osteoclasts and decreases the bone-forming process of osteoblasts [4]. The key mechanism which activates the osteoclast resorption process is the receptor activator of the nuclear factor- $\mathrm{kB}$ (RANK)/RANK ligand (RANKL) pathway [3]. This pathway is an important target for modern therapies.

\section{Materials and Methods}

A systematic review of the MEDLINE database was performed for articles published between 2011 and 2021 containing the terms "loosening hip". We included meta-analysis, randomized controlled trials, reviews, and systematic reviews. The authors reviewed the abstract of each article and only English-written articles were considered. All studies involving preoperative, intraoperative and postoperative factors that affect aseptic loosening in cementless total hip arthroplasty were included. More specific, implant properties (design, material, bearing surfaces), surgical factors, patient-related factors (comorbidities, demographics, genetics, habits), postoperative protocol (activities, weight-bearing), and use of perioperative drugs (antiosteoporotic drugs, opioids, statins, beta-blockers) were all included in our review. Studies on the aseptic loosening of both the acetabular component and the femoral stem were taken into account. Regarding the exclusion criteria, studies where only physiopathology, diagnosis or treatment of aseptic loosening were addressed were not included in our review. Moreover, only studies performed on cementless primary total hip replacements were included, while loosening of mega-prosthesis, hip revisions, hemiarthroplasties or hip resurfacing were not considered. The PRISMA flowchart is available in Figure 1. 


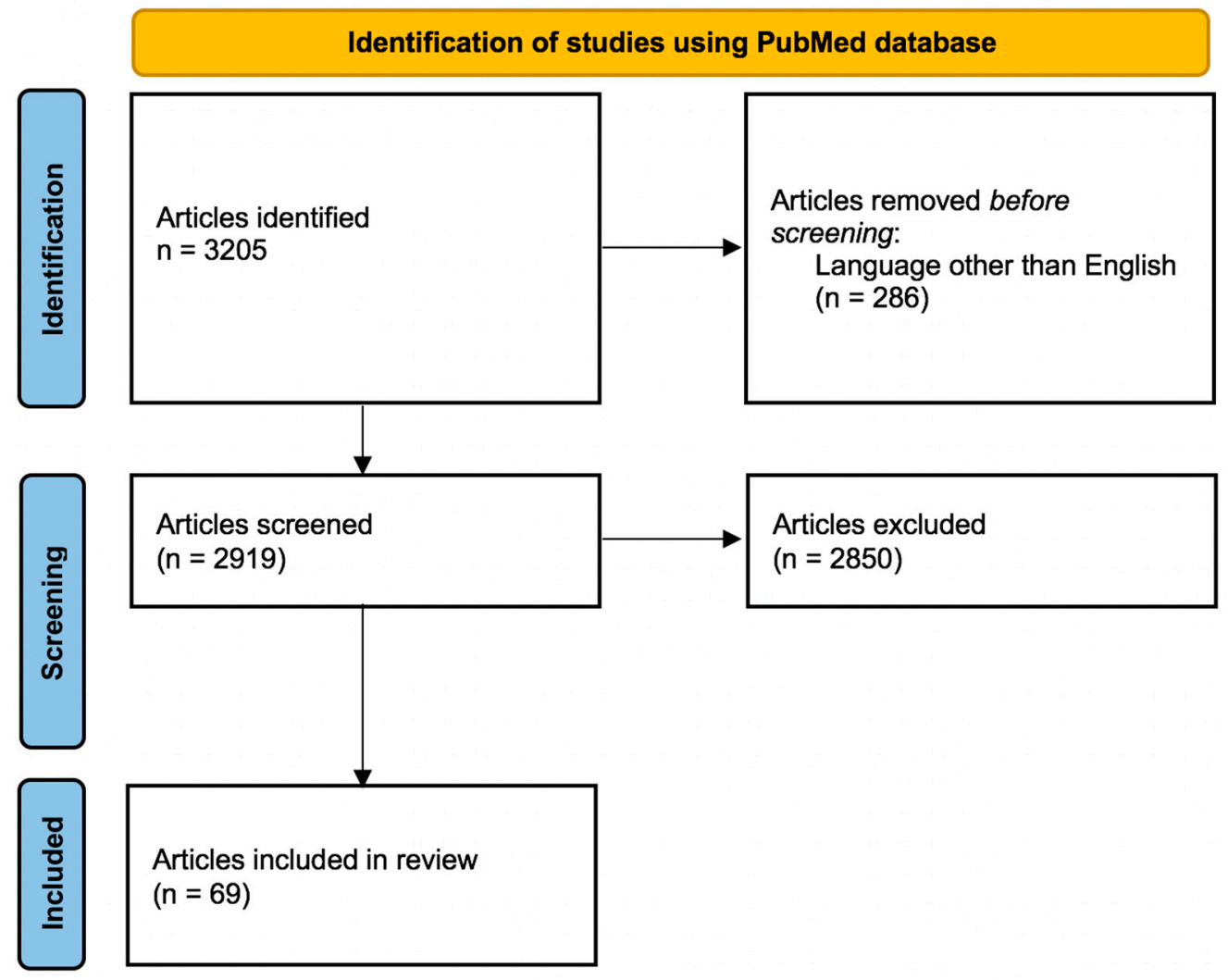

Figure 1. Flowchart showing methodology for the review of studies dealing with the factors affecting aseptic loosening in cementless total hip arthroplasty.

\section{Implant Properties}

The cementless total hip replacements systems are made up of four elements: the acetabular cup, insert, femoral head, and femoral stem. The most common alloy used in acetabular cups and femoral stems is $90 \mathrm{Ti}-6 \mathrm{Al}-4 \mathrm{~V}$ ELI. The acetabular insert can be made up of polyethylene or ceramic, while the femoral head can be made up of metal alloy or ceramic. The interaction of the femoral head and the insert is called the bearing surface. The bearing surfaces available today are ceramic-on-ceramic, ceramic-on-polyethylene and metal-on-polyethylene. There are three main characteristics of the implant which can influence the rate of aseptic loosening: implant design, alloy, and surface treatment.

Implant design has a direct impact on the survivorship of an uncemented total hip replacement according to multiple studies. Different femoral stem designs, which can be classified according to the Mont group, have different contact areas between the implant and bone [6]. So far, there have been described three generations of acetabular cups and seven femoral stem types [6]. The contact area can affect the primary osseointegration process and even further, the rate of aseptic loosening.

The metal alloys used directly influence the implant's biocompatibility, Young's modulus of elasticity, strength, and corrosion resistance, which all have a great impact on implant survivorship, as previously shown [7]. Moreover, surface treatments such as hydroxyapatite coating, acid etching, alkali heat treatment, plasma treatment, ion implementation, sandblasting, and nanotechnology can prevent aseptic loosening by affecting the primary osseointegration process [7]. We will further describe the most recommended implant characteristics in terms of reducing the rate of aseptic loosening.

\subsection{Acetabular Cup}

\subsubsection{Alloy}

Trabecular metal acetabular cups have gained a lot of popularity in the last decade. This alloy showed significantly less radiolucency when compared to porous-coated titanium 
acetabular cups, according to a study performed by Wegrzyn et al. on 113 patients [8]. Moreover, it reduces the risk of aseptic loosening compared to non-trabecular metal cups, as shown in a study on 12,800 primary THAs at a five-year follow-up [9].

\subsubsection{Surface Treatment}

Hydroxyapatite-coated cups have a similar risk for aseptic loosening as the uncoated ones, as shown by a study on 28,605 THAs from the Nordic Arthroplasty Register Association [10]. On the other hand, a study on 20,993 primary THA with highly porous acetabular components has shown a lower incidence of aseptic loosening in long term [6]. On the contrary, Palomäki et al., after analyzing 6080 primary THAs, showed that the ultraporous-coated acetabular component has an increased risk of revision compared to conventional uncemented cups [11].

\subsubsection{Design}

Acetabular cups without screw holes have a lower rate of revision compared to ones with screw holes, as shown by Otten et al. in a study on 22,725 primary total hip replacements [12]. The authors showed that the rate of aseptic loosening was not statistically significant between the two, but a limitation of the study was a mean follow-up of only 3.4 years (0-18) [12]. On the other hand, randomized clinical trial on 100 patients showed no difference between solid cups and cluster hole cups at 10 years follow-up [13].

Moreover, Keurentjes et al. performed a meta-analysis on the cumulative survival at 10 years to study the rate of aseptic loosening [14]. The following acetabular cups had the lowest rate of aseptic loosening, accordingly: Weber Hemispheric ${ }^{\circledR}$, Trabecular Metal Monoblock Acetabular Component System ${ }^{\circledR}$, JRI Threaded Cup ${ }^{\circledR}$, Fitmore ${ }^{\circledR}$, Conserve Plus ${ }^{\circledR}$, Morscher Press Fit ${ }^{\circledR}$, Zweymuller-Alloclassic Screw Cup ${ }^{\circledR}$, Arthropor ${ }^{\circledR}$, ACS Triloc $+{ }^{\circledR}, \operatorname{Titan}^{\circledR}$ and Spectron ${ }^{\circledR}[14]$.

\subsection{Femoral Stem}

\subsubsection{Alloy}

Titanium alloy stems have almost half of the proximal bone loss compared to cobaltchromium (CoCr) stems, according to a systematic analysis performed by Knutsen et al. [15].

\subsubsection{Surface Treatment}

Hydroxyapatite coating did not influence the revision rate at 10 years when compared to porous coating or rough sand-blasted stems, as shown by a study that analyzed 152,410 primary total hip replacements from the Nordic Arthroplasty Register [16]. Nevertheless, a meta-analysis by Chen et al. showed that although the survival rate of hydroxyapatite coating is similar to porous coating, the femoral osteolysis is greater in the porous group [17]. Cementless plasma-sprayed porous titanium hydroxyapatite stems have a $98.5 \%$ survivorship in patients aged 70 or older for femoral neck fractures, on a study performed on 293 patients (301 hips) [18].

\subsubsection{Design}

The femoral stems are divided into seven types, according to geometry, as following: type 1 (straight stem, single wedge), type 2 (straight stem, double wedge), type 3 (straight stem, tapered), type 4 (straight stem, cylindrical, fully coated), type 5 straight stem, (modular), type 6 (curved stem, anatomic stem) and type 7 (short stem) [19]. Type 1, type 2, type 6 and type 7 have an exclusively metaphyseal fixation, while type 3 and type 5 have a metaphyseal and diaphyseal fixation [19]. Type 4 has a primarily diaphyseal fixation. A study in 2011 by Khanujah et al. showed that types 1, 2, 4 and 7 femoral stems have better survival, as follows: $98.8 \%$ at 17 years; $99.2 \%$ at 17 years, $97.9 \%$ at 15 years and $98.2 \%$ at 10 years, respectively [19]. Nevertheless, type 1, type 2 and type 4 are associated with a higher rate of stress shielding and thigh pain [19]. 
Some shortened and shoulderless double-taper press-fit stems have a high rate of aseptic loosening (1,4\% at five years), as shown by Wagner et al., in a study on 517 Dorr type A patients [20]. Straight stems had less bone loss compared to anatomical, tapered, and press-fit designs, according to a systematic analysis performed by Knutsen et al. [15]. Regarding the femoral sizes, smaller Corail stem (sizes 8 and 9) have four times the rate of revision as compared to larger femoral sizes (10-20 stems) as found by a study on 42,265 primary THAs [21].

According to a meta-analysis performed by Keurentjes et al., the lowest rate for aseptic loosening was found in the following stems: ABG $\mathrm{I}^{\circledR}$, Osteonics Cementless ${ }^{\circledR}, \mathrm{R}-\mathrm{B}$ Interlok ${ }^{\circledR}$, Zweymuller Alloclassic $^{\circledR}$, Freeman Cementless ${ }^{\circledR}$, Stanmore Custom Mare ${ }^{\circledR}$, MS$30^{\circledR}$, Corail $^{\circledR}$ Profile Porous ${ }^{\circledR}$, Bi-Metric $^{\circledR}$, Mallory-Head Cementless ${ }^{\circledR}$, Taperloc ${ }^{\circledR}$, Furlong $^{\circledR}$, CLS Spotorno ${ }^{\circledR}$ and Titan $^{\circledR}[14]$.

\subsection{Bearing Surfaces}

The micromotion between the acetabular cup and inlay produces wear debris which generate a biologic host response responsible for a periprosthetic bone loss that further leads to aseptic loosening [22].

Ceramic-on-highly cross-linked polyethylene (CoPx) has the best survivorship (0.54/ 100-component-years), followed by metal-on-polyethylene according to New Zealand Joint Registry study performed on 106,139 THAs [23]. This result is according to another study by Hu et al. performed on 974 primary THAs [23]. Metal-on-metal bearings had the lowest survivorship (1.43/100-component-years) [23]. This statement is supported by a meta-analysis performed by Lee et al. in which metal on metal (MOM) was associated with a higher risk of revision compared to a ceramic-on-ceramic (COC) bearing [24]. When comparing ceramic-on-polyethylene and ceramic-on-ceramic, a meta-analysis by Shang et al. on 2702 patients showed that the results are comparable in terms of revision rate at a long-term follow-up [25]. On the other hand, an analysis of the Dutch Registry on 33,454 patients pointed out a higher 2-year cup revision rate in the ceramic-on-ceramic group compared to ceramic-on-polyethylene $(\mathrm{HR}=0.475)$ [26]. A study on 11,096 patients with primary THAs showed no difference at an 8.7-year follow-up in revision rates between ceramicon-ceramic compared to metal-on-polyethylene [6]. On the contrary, on a follow-up of 20 years, ceramic-on-ceramic bearing had a lower rate of aseptic revision rate compared to metal-on-polyethylene $[27,28]$. These studies suggest that the best bearing in terms of survivorship have the following order: ceramic-on-polyethylene, ceramic-on-ceramic, metal-on-polyethylene and metal-on-metal.

Another bearing which is gaining increasing interest in recent years is the dual mobility construct. A review which included 448 primary dual mobility cups at a mean follow-up of 7.6 years showed that aseptic loosening rate was less compared to the unipolar group (OR $=1.21, p=81)$ [29,30]. Another study on 150 primary dual mobility THAs and 166 unipolar THAs at a mean follow-up of 31 months showed that dual mobility bearings had a lower rate of aseptic loosening (0.7\% vs. 5\%) [30]. An analysis of the Nordic Arthroplsaty Register Association on over 2000 matched patients concluded that there was no difference in overall risk of revision between dual mobility cups and metal-on-polyethylene or ceramic-on-polyethylene bearings [31]. Another review on mid-term follow-up of more than 500 dual mobility cups showed that there was no statistically significant difference in aseptic loosening rates compared to unipolar cups [32]. A systematic review of Darrith et al. on more than 10,000 primary dual mobility cups resulted in an aseptic loosening incidence of $1.3 \%$ at a mean follow-up of 8.5 years [33]. The only long-term study we found included 85 dual-mobility total hip replacements performed on obese patients and no aseptic loosening was found at a follow-up of 15 years [29,30]. More long-term follow-up studies are needed in order to properly assess the aseptic loosening rate.

Jaeger et al. tested three different locking mechanisms between the cup and inlay: Allofit ${ }^{\circledR}-S$ Alloclassic ${ }^{\circledR}$ with cross-linked Durasul ${ }^{\circledR}$-PE liner (Zimmer Biomet); Pinnacle ${ }^{\circledR}$ Multihole combinates with a cross-linked Marathon ${ }^{\circledR}$-PE liner (DePuy Synthes) and Plasmafit ${ }^{\circledR}$ 
Plus7 with a conventional ultra-high-molecular-weight polyethylene (UHMWPE) liner (Aesculap) [20]. The micromotion was less in the Aesculap combination, followed by DePuy and Zimmer Biomet [22].

Other UHMWPE have been recently introduced, with promising results, such as the $\mathrm{X}$-linked UHMWPE, but further studies are needed in order to decide on the long-term effect on polyethylene wear and aseptic loosening.

\section{Surgical Factors}

\subsection{Surgeon}

In terms of surgeon, a study on 116 low revision rate surgeons $(<3.84 \%$ revision rate at 5 years) and 433 other surgeons, showed that low revision rate surgeons use fewer types of implants compared to the higher revision rate surgeons [28,34]. Moreover, the same study pointed out that lower revision rate surgeons were more likely to conduct more than 100 total hip replacements per year [34]. In terms of experience, lower revision rate surgeons were related to a higher experience in terms of years and cases per year, but the differences were subtle [34].

\subsection{Hospital}

Regarding teaching-hospitals vs. non-teaching hospitals, it was proved that resident training does not influence the complication rate at a mean follow-up of 97 months [35].

\subsection{Approach}

One of the main factors affecting the rate of aseptic loosening is, surprisingly, the approach. A study on 48,716 primary cementless THAs showed that the anterior approach had the highest rate for femoral stem loosening [36]. The same result was found by a meta-analysis performed by Huang et al. in 2021 and by Hoskins et al. on a study of 122,345 patients, who showed a higher rate of early major revisions [37,38]. A meta-analysis by Docter et al. showed that the posterior approach has the lowest risk for loosening when compared to lateral and anterolateral approaches [39]. On the contrary, a study from the Norwegian Arthroplasty Register on 21,860 THAs showed that the risk of revision was not increased in the case of anterior minimally invasive surgery or anterolateral approach when compared to lateral or posterior approaches [40].

\subsection{Acetabular Screws}

Regarding the use of acetabular screws, they can lower the risk of revision surgery as shown by Natera et al. on 749 cases of primary THAs [41].

\section{Patient-Related Factors}

\subsection{Demographics}

A study on 63,158 patients showed that when performing the surgery at the age of under 70 years old, the rate of revision is up to $35 \%$, compared to $5 \%$ in the case of patients aged 70 years or older when performing the THA [42]. A study showed that female patients have a significantly increased periarticular remodeling (Ot.Lac.Ar = osteocyte lacunae area) compared to male patients in the samples retrieved during total hip replacement revision surgery [43]. On the other hand, a systematic review showed that seven out of eight papers resulted in an increased risk for revision surgeries in male patients [44].

\subsection{Genetics}

Several genetic variations of single-nucleotide polymorphisms (SNPs) are associated with an increased risk of aseptic loosening, as follows: IFIT2/IFIT3 (odds ratio $=21.6$ ), CERK (odds ratio $=12.6$ ) and PAPPA (odds ratio $=14$ ) [45]. Another study supports the importance of genome impact on osteolysis susceptibility [46]. A systematic review performed by Del Buono et al. showed overexpression of the following genes in the cases 
of aseptic loosening: TNF-238 A allele, IL6-174 G allele, interleukin (IL)-6 (-597) and (-572), TNF-alfa promoter (-308G-A), and MMP-1 promoting gene [47].

\subsection{Comorbidities}

\subsubsection{Obesity}

Obesity increases the overall risk of early revision of primary THAs due to aseptic loosening 4.7-fold, as shown by Electricwala et al. on a study on 273 revision THAs [48]. Moreover, a study on 684 revision THAs showed that obesity increases the risk of early aseptic loosening in primary THAs to $30 \%$, compared to $18 \%$ in nonobese patients, [49]. A meta-analysis by Haverkamp et al. including 15 studies, showed that obese patients have an odds ratio of 0.64 to develop aseptic loosening compared to nonobese patients [50].

\subsubsection{Hyperglycemia}

A high preoperative hyperglycemia $(>180 \mathrm{mg} / \mathrm{dl}$ ) increases the risk of revision due to aseptic loosening $(\mathrm{HR}=4.95 \%)$ [51].

\subsubsection{Rheumatoid Arthritis}

In the case of rheumatoid arthritis, acetabular cup migration is significantly higher compared to osteoarthritic patients [52]. Another study showed that higher inflammatory disease activity in patients with rheumatoid arthritis increases the risk for radiographic loosening $[52,53]$.

\subsubsection{Avascular Necrosis of the Femoral Head}

When performing a DXA scan of the periprosthetic area in the case of avascular necrosis of the femoral head, Gruen zones 1 and 7 had a statistically significant lower BMD when compared to primary osteoarthritis [54]. This can lead to an impaired implant fixation.

\subsubsection{Hip Dysplasia}

When hip dysplasia is present, nonmodular conical stem design increases the risk of cup aseptic loosening (2.5\%) [55].

\subsubsection{Sickle Cell Disease and Hemophilia}

A study on 881 patients with sickle cell disease showed that there is an increased risk of aseptic loosening at 2 years compared to the control group [56]. Hemophilic patients have a $10.2 \%$ risk for aseptic loosening at a mean follow-up of 11.5 years [57]. Parkinson's disease also increases the risk of aseptic loosening $(6.1 \%)$ in the first year postoperatively [58]. Patients with chronic liver disease (CLD) have a $7 \%$ risk for aseptic loosening at a mean follow-up of 13.5 months, which is higher compared to the control group [59]. On the other hand, hemodialysis almost doubles the rate of aseptic loosening in total hip replacements, according to 25 studies involving 755 hips in 534 patients [60].

\subsubsection{Spinal Fusion}

Regarding previous surgeries, the presence of lumbar spinal fusion increases the risk for aseptic loosening ( $\mathrm{OR}=3.42$ at 90 days and $\mathrm{OR}=4.68$ at 1 year) [61]. Another factor that can increase the risk for aseptic loosening is a previous hip arthroscopy $(\mathrm{OR}=2.18)$ [62].

\subsection{Smoking}

It increases the risk for aseptic loosening by three times, as Lee et al. pointed out [24]. Bhaveen et al. showed that the overall implant survival of primary total hip arthroplasty at a mean follow-up of 51 months is $99 \%$ in the non-smoker group and $92 \%$ in the smoker group [63]. In addition, smoking cessation within two months before surgery does not add any benefits to the outcome of a THA according to a meta-analysis by Myers et al. [63]. Nevertheless, there was one randomized trial on 120 patients which showed that smoking 
cessation 6-8 weeks before surgery reduces the postoperative morbidity including woundrelated complications and the need of a revision surgery $[63,64]$.

\section{Postoperative Protocol}

Early full weight-bearing has not been shown to affect the bone mineral density around the implant at 5 years postoperatively, as compared to partial weight-bearing [41]. Nevertheless, high-impact activities have an odds ratio of 4.24 to develop aseptic loosening, compared to a patient with medium or low activity levels [65].

\section{Perioperative Drugs}

\subsection{Antiosteoporotic Drugs}

Denosumab is a monoclonal antibody recently introduced in the treatment of osteoporosis. It protects against periprosthetic bone loss after THAs, but its effect diminishes after the administration is stopped [66]. Bisphosphonates decrease the rate of THA revision (2.8\% vs. 5.3\%), in a study performed on 56,043 patients in Korea [67]. Another study on 95,392 patients showed that oral bisphosphonates reduce the risk of revision surgery by $59 \%$ when the treatment is started after the primary arthroplasty surgery [68]. Muratore et al. showed in a study on 35 female patients a statistically significant higher BMD around the femoral implant when treated with ibandronate $3 \mathrm{mg}$ iv. within five days after surgery, followed by oral ibandronate $150 \mathrm{mg} /$ months, plus calcium carbonate $(1 \mathrm{~g})$ and vitamin D (880 IU) supplementation [69]. A meta-analysis performed by Zhao et al. showed that bisphosphonates decrease both early and late periprosthetic bone resorption in the main load-bearing zones [70].

\subsection{Opioids}

Preoperative use of opioids is significantly associated with an increased rate of aseptic loosening $(\mathrm{OR}=1.3)$ [71]. Although the mechanism is not clearly understood, an explanation could be provided by the increase of the proinflammatory cytokines by opioids [71].

\subsection{Statins}

As shown by the Danish Hip Arthroplasty Registry, statins reduce the risk of revision arthroplasty [72]. The mechanism can be explained by reduced cytokine production by the administration of statins. Valles et al. showed that statins down-regulate the HMGCoA/GGPP/RhoA/ROCK pathway, therefore reducing the proinflammatory state and decreasing the osteolysis around the implant [73]. Furthermore, a study on 735 primary THAs showed that statins reduce femoral osteolysis 5 years after the surgical procedure [74]

\subsection{Beta-Blockers}

These are associated with a lower risk of aseptic loosening in THAs $(\mathrm{OR}=0.112)$ [75]. The effect can be due to the interaction between the adrenergic system and bone metabolism [74,75]. Previous studies have shown that beta-blockers decrease the risk of hip fracture and increase bone mineral density (BMD) [75]. All these effects are mostly due to inhibition effect of the the beta-blockers on osteoclastic activity [75].

\subsection{Other Drugs}

Different drugs were shown to have a positive effect on either the reduction of periimplant osteolysis or enhancement of osteoblastic activities in experimental models include Lactobacillus casei (probiotic), enalapril, cimfugin, narginin, XCL1, curcumin, lentivirus TNF-alpha gene therapy, and scutellarin [76-84].

Moreover, the inhibition of ferroptosis, a process generation aseptic loosening, with a specific inhibitor (Ferrostatin-1) reduces particle-induced ferroptosis in vitro, while overexpression of Nrf2 by siKeap1 or Nrf2 activator Oltipraz upregulates antioxidant response elements and suppressed ferroptosis in osteoblasts [85]. 
Tool-like Receptors (TRLs) recognizing pathogen-associated microbial patterns (PAMPSs) are involved in the implant loosening [86]. IRAK-4 is overexpressed in the aseptic loosening interface membranes when compared to osteoarthritic patients [87].

\section{Experimental Studies on the Process of Osseointegration}

When we compared the current data with a previous work of our team regarding the prevention of aseptic loosening, we found out that researchers and clinicians have added new recommendations in the last years, while the previous remained generally unchanged. A summary of the current recommendations is available in Table 1.

Table 1. Previous and recent recommendations regarding the factors affecting aseptic loosening.

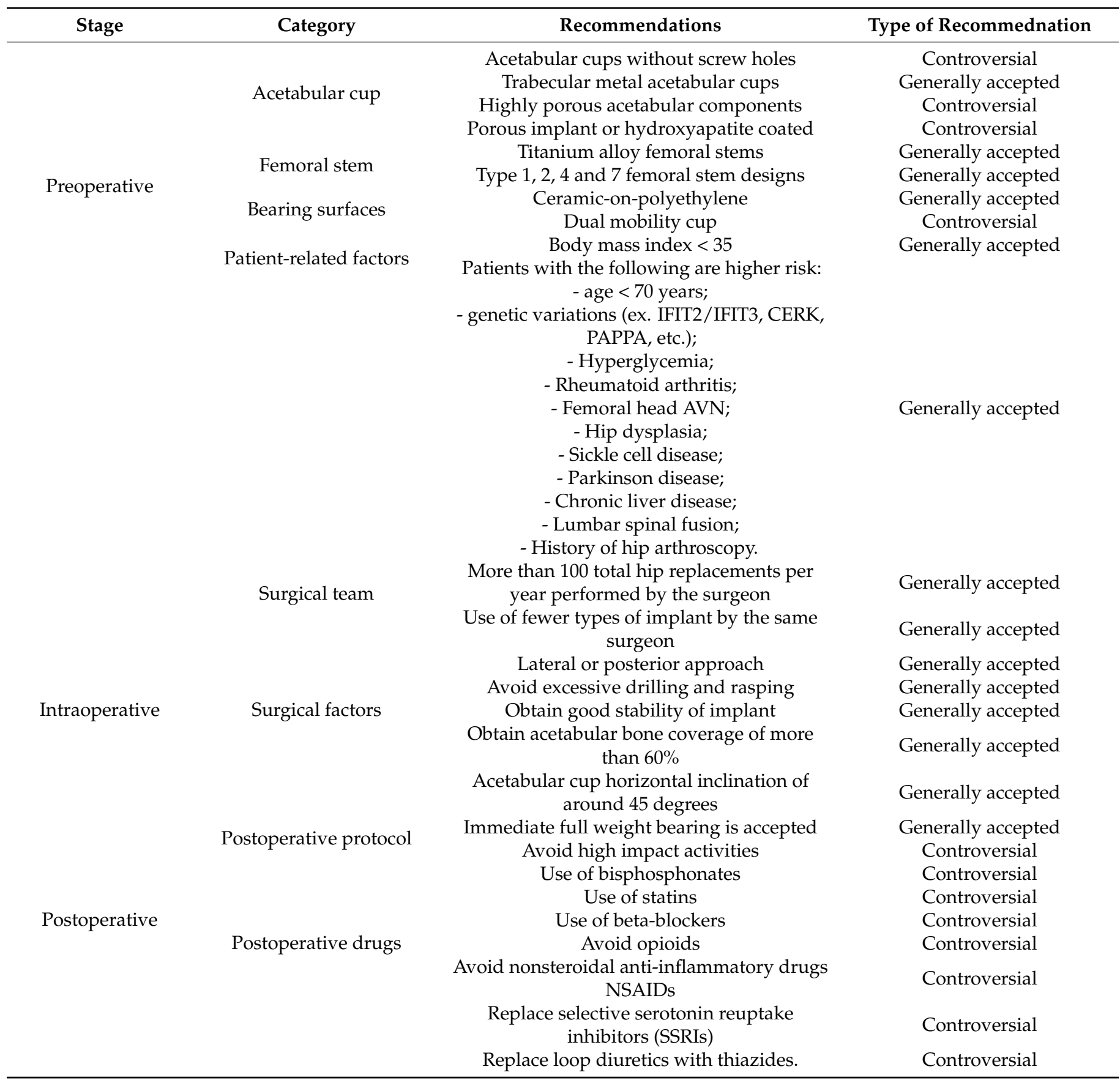


Although the studies which will be further discussed in this chapter are not specifically performed on aseptic loosening in the case of total hip arthroplasty, they are focused on the osseointegration process or survival rates, which are closely related to a decrease in aseptic loosening.

As previous studies showed, the recommended pore size for a better bone ingrowth is $600 \mu \mathrm{m}$, when compared to $300 \mu \mathrm{m}$ and $900 \mu \mathrm{m}$ [87]. The impact of osteoporosis on the total hip arthroplasty aseptic loosening has not been decided, but studies show a delayed osseointegration process due to a decreased bone metabolism and estrogen deficiency [7]. Other comorbidities to impact hip replacement survival are cardiovascular disease and psychotic disorders [7].

Surgeon's experience is important in decreasing the revision rate of total hip replacements according to Fender et al. [83]. They showed that surgeons who perform 30 THAs per year are more likely to have a higher revision rate compared to those with over 60 THAs per year [88].

In terms of surgical technique, the main purposes are ensuring good stability and good coverage of the implant, while avoiding any excessive reaming and rasping [7]. Moreover, the use of worn reamers and rasps can alter the bone surrounding the implant, thus reducing the osseointegration process $[7,89]$.

Although non-steroidal anti-inflammatory drugs (NSAIDs) have not been related to an increased rate of aseptic loosening, they have been linked to a decrease in the osseointegration process [7]. As a result, until more data regarding its safety are available, we recommend against the use of NSAIDs in the postoperative period of THAs. Other drugs in similar situations are selective serotonin reuptake inhibitors (SSRIs) and loop diuretics, which are recommended to be replaced when possible [7].

\section{Conclusions}

Aseptic loosening is a complication that generates a lot of interest in the research community due to its importance. There are currently various methods by which the aseptic loosening rate can be reduced, such as implant characteristics, surgical technique, as well as patient-related and postoperative factors. As there has been a lot of research in the field of osseointegration and aseptic loosening, we consider that an update is important for the clinician to be able to use all of the available techniques to prevent this serious complication. Moreover, the data in this review paper could help researchers find new ways of approaching the treatment of aseptic loosening.

A summary of the generally accepted recommendations include the use of trabecular metal acetabular cups, titanium alloy femoral stems, certain types of femoral stem design (types 1,2,4 and 7), and ceramic-on-polyethylene bearing surfaces.

In addition, surgeons performing more than 100 THAs per year and are consistent with their implant type tend to have a lower revision rate. Surgical factors which limit aseptic loosening include lateral and posterior approaches, good implant stability, at least $60 \%$ of acetabular cup bone coverage and an inclination of around 45 degrees. Postoperatively, immediate full weight bearing is accepted.

It is also important to inform on the higher risk of revision the patients with obesity, less than 70 years old, hyperglycemia, rheumatoid arthritis, avascular necrosis of the femoral head, hip dysplasia, sickle cell disease, Parkinson disease, chronic liver disease, lumbar spinal fusion, some genetic variations and a history of hip arthroscopy.

Author Contributions: Conceptualization, D.A., H.B., D.C., A.M. and D.P.; methodology, D.A., D.O.D., O.L.; formal analysis, D.A., D.O.-D., C.P.; investigation, D.A., D.O.-D., O.L., C.P.; writing-original draft preparation, D.A., D.O.-D., C.P., D.C., A.M.; writing-review and editing, D.P., H.B.; supervision D.P. and H.B.; project administration, D.A.; funding acquisition, D.A. All authors have read and agreed to the published version of the manuscript.

Funding: This work was supported by a grant of the Romanian Ministry of Education and Research, CNCS-UEFISCDI, project number PN-III-P1-1.1-PD-2019-0124, within PNCDI III. 


\section{Institutional Review Board Statement: Not applicable.}

Informed Consent Statement: Not applicable.

Conflicts of Interest: The authors declare no conflict of interest.

\section{References}

1. Hailer, N.P.; Garellick, G.; Kärrholm, J. Uncemented and cemented primary total hip arthroplasty in the Swedish Hip Arthroplasty Register. Acta Orthop. 2010, 81, 34-41. [CrossRef] [PubMed]

2. Haragus, H.; Prejbeanu, R.; Poenaru, D.V.; Deleanu, B.; Timar, B.; Vermesan, D. Cross-cultural adaptation and validation of a patient-reported hip outcome score. Int. Orthop. 2018, 42, 1001-1006. [CrossRef] [PubMed]

3. Abu-Amer, Y.; Darwech, I.; Clohisy, J.C. Aseptic loosening of total joint replacements: Mechanisms underlying osteolysis and potential therapies. Arthritis Res. 2007, 9 (Suppl. S1), S6. [CrossRef] [PubMed]

4. Parithimarkalaignan, S.; Padmanabhan, T.V. Osseointegration: An update. J. Indian Prosthodont. Soc. 2013, 13, 2-6. [CrossRef]

5. Goodman, S.B.; Gallo, J. Periprosthetic Osteolysis: Mechanisms, Prevention and Treatment. J. Clin. Med. 2019, 8, 2091. [CrossRef]

6. Hoskins, W.; Rainbird, S.; Holder, C.; Graves, S.E.; Bingham, R. Revision for Aseptic Loosening of Highly Porous Acetabular Components in Primary Total Hip Arthroplasty an Analysis of 20,993 Total Hip Replacements. J. Arthroplast. 2021, 37, 312-315. [CrossRef]

7. Apostu, D.; Lucaciu, O.; Berce, C.; Lucaciu, D.; Cosma, D. Current methods of preventing aseptic loosening and improving osseointegration of titanium implants in cementless total hip arthroplasty: A review. J. Int. Med. Res. 2018, 46, 2104-2119. [CrossRef]

8. Wegrzyn, J.; Kaufman, K.R.; Hanssen, A.D.; Lewallen, D.G. Performance of Porous Tantalum vs. Titanium Cup in Total Hip Arthroplasty: Randomized Trial with Minimum 10-Year Follow-Up. J. Arthroplast. 2015, 30, 1008-1013. [CrossRef]

9. Matharu, G.S.; Judge, A.; Murray, D.W.; Pandit, H.G. Trabecular Metal Acetabular Components Reduce the Risk of Revision Following Primary Total Hip Arthroplasty: A Propensity Score Matched Study From the National Joint Registry for England and Wales. J. Arthroplast. 2018, 33, 447-452. [CrossRef]

10. Lazarinis, S.; Mäkelä, K.T.; Eskelinen, A.; Havelin, L.; Hallan, G.; Overgaard, S.; Pedersen, A.B.; Kärrholm, J.; Hailer, N.P. Does hydroxyapatite coating of uncemented cups improve long-term survival? An analysis of 28,605 primary total hip arthroplasty procedures from the Nordic Arthroplasty Register Association (NARA). Osteoarthr. Cartil. 2017, 25, 1980-1987. [CrossRef]

11. Palomäki, A.; Hemmilä, M.; Laaksonen, I.; Matilainen, M.; Eskelinen, A.; Haapakoski, J.; Puhto, A.P.; Kettunen, J.; Manninen, M.; Mäkelä, K. Implant Survival of 6,080 Tritanium Cups in Primary Total Hip Arthroplasty: Data from the Finnish Arthroplasty Register from 2009 to 2017. J. Bone Jt. Surg. Am. 2020, 102, 1177-1185. [CrossRef] [PubMed]

12. Otten, V.; Mukka, S.; Nilsson, K.; Crnalic, S.; Kärrholm, J. Uncemented cups with and without screw holes in primary THA: A Swedish Hip Arthroplasty Register study with 22,725 hips. Acta Orthop. 2019, 90, 258-263. [CrossRef] [PubMed]

13. Gallen, R.A.; Khan, R.J.K.; Haebich, S.J.; Karamfiles, S.H.; Khan, H. Solid Cup vs Cluster Hole in Total Hip Arthroplasty: A 10-Year Randomized Control Trial. J. Arthroplast. 2018, 33, 1113-1119. [CrossRef] [PubMed]

14. Keurentjes, J.C.; Pijls, B.G.; Van Tol, F.R.; Mentink, J.F.; Mes, S.D.; Schoones, J.W.; Fiocco, M.; Sedrakyan, A.; Nelissen, R.G. Which implant should we use for primary total hip replacement? A systematic review and meta-analysis. J. Bone Jt. Surg. Am. 2014, 96 (Suppl. S1), 79-97. [CrossRef]

15. Knutsen, A.R.; Lau, N.; Longjohn, D.B.; Ebramzadeh, E.; Sangiorgio, S.N. Periprosthetic femoral bone loss in total hip arthroplasty: Systematic analysis of the effect of stem design. Hip Int. 2017, 27, 26-34. [CrossRef]

16. Hailer, N.P.; Lazarinis, S.; Mäkelä, K.T.; Eskelinen, A.; Fenstad, A.M.; Hallan, G.; Havelin, L.; Overgaard, S.; Pedersen, A.B.; Mehnert, F.; et al. Hydroxyapatite coating does not improve uncemented stem survival after total hip arthroplasty! Acta Orthop. 2015, 86, 18-25. [CrossRef]

17. Chen, Y.L.; Lin, T.; Liu, A.; Shi, M.M.; Hu, B.; Shi, Z.I.; Yan, S. Does hydroxyapatite coating have no advantage over porous coating in primary total hip arthroplasty? A meta-analysis. J. Orthop. Surg. Res. 2015, 10, 21. [CrossRef]

18. Piolanti, N.; Neri, E.; Bonicoli, E.; Parchi, P.D.; Marchetti, S.; Manca, M.; Bonini, L.; Banci, L.; Scaglione, M. Use of a PlasmaSprayed Titanium-Hydroxyapatite Femoral Stem in Hip Arthroplasty in Patients Older than 70 Years. Is Cementless Fixation a Reliable Option in the Elderly? J. Clin. Med. 2021, 10, 4735. [CrossRef]

19. Wagner, M.; Schönthaler, H.; Endstrasser, F.; Dammerer, D.; Nardelli, P.; Brunner, A. Mid-Term Results After 517 Primary Total Hip Arthroplasties With a Shortened and Shoulderless Double-Taper Press-Fit Stem: High Rates of Aseptic Loosening. J. Arthroplast. 2021, 37, 97-102. [CrossRef]

20. Khanuja, H.S.; Vakil, J.J.; Goddard, M.S.; Mont, M.A. Cementless Femoral Fixation in Total Hip Arthoplasty. J. Bone Jt. Surg. 2021, 93, 500-509. [CrossRef]

21. Hoskins, W.T.; Bingham, R.J.; Lorimer, M.; de Steiger, R.N. The Effect of Size for a Hydroxyapatite-Coated Cementless Implant on Component Revision in Total Hip Arthroplasty: An Analysis of 41,265 Stems. J. Arthroplast. 2020, 35, 1074-1078. [CrossRef] [PubMed]

22. Jaeger, S.; Uhler, M.; Schroeder, S.; Beckmann, N.A.; Braun, S. Comparison of Different Locking Mechanisms in Total Hip Arthroplasty: Relative Motion between Cup and Inlay. Materials 2020, 13, 1392. [CrossRef] [PubMed] 
23. Sharplin, P.; Wyatt, M.C.; Rothwell, A.; Frampton, C.; Hooper, G. Which is the best bearing surface for primary total hip replacement? A New Zealand Joint Registry study. Hip Int. 2018, 28, 352-362. [CrossRef] [PubMed]

24. Lee, Y.K.; Yoon, B.H.; Choi, Y.S.; Jo, W.L.; Ha, Y.C.; Koo, K.H. Metal on Metal or Ceramic on Ceramic for Cementless Total Hip Arthroplasty: A Meta-Analysis. J. Arthroplast. 2017, 31, 2637-2645.e1. [CrossRef]

25. Shang, X.; Fang, Y. Comparison of Ceramic-on-Ceramic vs. Ceramic-on-Polyethylene for Primary Total Hip Arthroplasty: A Meta-Analysis of 15 Randomized Trials. Front. Surg. 2021, 16, 751121. [CrossRef]

26. van Loon, J.; Sierevelt, I.N.; Spekenbrink-Spooren, A.; Opdam, K.T.; Poolman, R.W.; Kerkhoffs, G.M.; Haverkamp, D. Higher risk of 2-year cup revision of ceramic-on-ceramic versus ceramic-on-polyethylene bearing: Analysis of 33,454 primary press-fit total hip arthroplasties registered in the Dutch Arthroplasty Register (LROI). Hip Int. 2022, 11207000211064975. [CrossRef] [PubMed]

27. Varnum, C. Outcomes of different bearings in total hip arthroplasty-Implant survival, revision causes, and patient-reported outcome. Dan Med. J. 2017, 64, B5350.

28. Vendittoli, P.A.; Shahin, M.; Rivière, C.; Barry, J.; Lavoie, P.; Duval, N. Ceramic-on-ceramic total hip arthroplasty is superior to metal-on-conventional polyethylene at 20-year follow-up: A randomised clinical trial. Orthop. Traumatol. Surg. Res. 2021, 107, 102744. [CrossRef] [PubMed]

29. Hernigou, P.; Trousselier, M.; Roubineau, F.; Bouthors, C.; Flouzat Lachaniette, C.H. Dual-mobility or Constrained Liners Are More Effective Than Preoperative Bariatric Surgery in Prevention of THA Dislocation. Clin. Orthop. Relat. Res. 2016, 474, 2202-2210. [CrossRef]

30. Berry, D.J.; Abdel, M.P. Dual-Mobility Constructs in Primary and Revision Total Hip Arthroplasty: A Systematic Review of Comparative Studies. J. Arthroplast. 2019, 34, 594-603. [CrossRef] [PubMed]

31. Kreipke, R.; Rogmark, C.; Pedersen, A.B.; Kärrholm, J.; Hallan, G.; Havelin, L.I.; Mäkelä, K.; Overgaard, S. Dual Mobility Cups: Effect on Risk of Revision of Primary Total Hip Arthroplasty Due to Osteoarthritis: A Matched Population-Based Study Using the Nordic Arthroplasty Register Association Database. J. Bone Jt. Surg. Am. 2019, 101, 169-176. [CrossRef] [PubMed]

32. Jonker, R.C.; van Beers, L.W.A.H.; van der Wal, B.C.H.; Vogely, H.C.; Parratte, S.; Castelein, R.M.; Poolman, R.W. Can dual mobility cups prevent dislocation without increasing revision rates in primary total hip arthroplasty? A systematic review. Orthop. Traumatol. Surg. Res. 2020, 106, 509-517. [CrossRef] [PubMed]

33. Darrith, B.; Courtney, P.M.; Della Valle, C.J. Outcomes of dual mobility components in total hip arthroplasty: A systematic review of the literature. Bone Jt. J. 2018, 100, 11-19. [CrossRef] [PubMed]

34. Hoskins, W.; Rainbird, S.; Lorimer, M.; Graves, S.E.; Bingham, R. What Can We Learn From Surgeons Who Perform THA and TKA and Have the Lowest Revision Rates? A Study from the Australian Orthopaedic Association National Joint Replacement Registry. Clin. Orthop. Relat. Res. 2021. Epub ahead of print. [CrossRef] [PubMed]

35. Bron, D.M.; Wolterbeek, N.; Poolman, R.W.; Kempen, D.H.; Delawi, D. Resident training does not influence the complication risk in total knee and hip arthroplasty. Acta Orthop. 2021, 92, 689-694. [CrossRef] [PubMed]

36. Hoskins, W.; Rainbird, S.; Peng, Y.; Graves, S.E.; Bingham, R. The Effect of Surgical Approach and Femoral Prosthesis Type on Revision Rates Following Total Hip Arthroplasty: An Analysis of the Most Commonly Utilized Cementless Stems. J. Bone Jt. Surg. Am. 2021, 104, 24-32. [CrossRef]

37. Huang, X.T.; Lium, D.G.; Jia, B.; Xu, Y.X. Comparisons between Direct Anterior Approach and Lateral Approach for Primary Total Hip Arthroplasty in Postoperative Orthopaedic Complications: A Systematic Review and Meta-Analysis. Orthop. Surg. 2021, 13, 1707-1720. [CrossRef]

38. Hoskins, W.; Bingham, R.; Lorimer, M.; Hatton, A.; de Steiger, R.N. Early Rate of Revision of Total Hip Arthroplasty Related to Surgical Approach: An Analysis of 122,345 Primary Total Hip Arthroplasties. J. Bone Jt. Surg. Am. 2020, 102, $1874-1882$. [CrossRef]

39. Docter, S.; Philpott, H.T.; Godkin, L.; Bryant, D.; Somerville, L.; Jennings, M.; Marsh, J.; Lanting, B. Comparison of intra and post-operative complication rates among surgical approaches in Total Hip Arthroplasty: A systematic review and meta-analysis. J. Orthop. 2020, 20, 310-325. [CrossRef]

40. Mjaaland, K.E.; Svenningsen, S.; Fenstad, A.M.; Havelin, L.I.; Furnes, O.; Nordsletten, L. Implant Survival After Minimally Invasive Anterior or Anterolateral Vs. Conventional Posterior or Direct Lateral Approach: An Analysis of 21,860 Total Hip Arthroplasties from the Norwegian Arthroplasty Register (2008 to 2013). J. Bone Jt. Surg. Am. 2017, 99, 840-847. [CrossRef]

41. Natera, L.; Valera, M.; Gómez, E.M.; Ibañez, N.; Crusi, X.; Sancho, R. Survival of hydroxyapatite-coated cups: Acetabular screws involve a lower rate of revision surgery due to aseptic loosening. Hip Int. 2017, 27, 153-161. [CrossRef] [PubMed]

42. Bayliss, L.E.; Culliford, D.; Monk, A.P.; Glyn-Jones, S.; Prieto-Alhambra, D.; Judge, A.; Cooper, C.; Carr, A.J.; Arden, N.K.; Beard, D.J.; et al. The effect of patient age at intervention on risk of implant revision after total replacement of the hip or knee: A population-based cohort study. Lancet 2017, 389, 1424-1430, Erratum in Lancet 2017, 389, 1398. [CrossRef]

43. Ormsby, R.T.; Solomon, L.B.; Stamenkov, R.; Findlay, D.M.; Atkins, G.J. Evidence for Gender-Specific Bone Loss Mechanisms in Periprosthetic Osteolysis. J. Clin. Med. 2019, 9, 53. [CrossRef]

44. Prokopetz, J.J.; Losina, E.; Bliss, R.L.; Wright, J.; A Baron, J.; Katz, J.N. Risk factors for revision of primary total hip arthroplasty: A systematic review. BMC Musculoskelet. Disord. 2012, 13, 251. [CrossRef]

45. Koks, S.; Wood, D.J.; Reimann, E.; Awiszus, F.; Lohmann, C.H.; Bertrand, J.; Prans, E.; Maasalu, K.; Martson, A. The Genetic Variations Associated With Time to Aseptic Loosening After Total Joint Arthroplasty. J. Arthroplast. 2020, 35, 981-988. [CrossRef] 
46. MacInnes, S.J.; Hatzikotoulas, K.; Fenstad, A.M.; Shah, K.; Southam, L.; Tachmazidou, I.; Hallan, G.; Dale, H.; Panoutsopoulou, K.; Furnes, O.; et al. The 2018 Otto Aufranc Award: How Does Genome-wide Variation Affect Osteolysis Risk After THA? Clin. Orthop. Relat. Res. 2019, 477, 297-309. [CrossRef] [PubMed]

47. Del Buono, A.; Denaro, V.; Maffulli, N. Genetic susceptibility to aseptic loosening following total hip arthroplasty: A systematic review. Br. Med. Bull. 2012, 101, 39-55. [CrossRef]

48. Electricwala, A.J.; Narkbunnam, R.; Huddleston, J.I., 3rd; Maloney, W.J.; Goodman, S.B.; Amanatullah, D.F. Obesity is Associated With Early Total Hip Revision for Aseptic Loosening. J. Arthroplast. 2016, 31 (Suppl. S9), 217-220. [CrossRef]

49. Goodnough, L.H.; Finlay, A.K.; Huddleston, J.I., 3rd; Goodman, S.B.; Maloney, W.J.; Amanatullah, D.F. Obesity Is Independently Associated With Early Aseptic Loosening in Primary Total Hip Arthroplasty. J. Arthroplast. 2018, 33, 882-886. [CrossRef]

50. Haverkamp, D.; Klinkenbijl, M.N.; Somford, M.P.; Albers, G.H.; van der Vis, H.M. Obesity in total hip arthroplasty-does it really matter? A meta-analysis. Acta Orthop. 2011, 82, 417-422. [CrossRef]

51. Maradit Kremers, H.; Schleck, C.D.; Lewallen, E.A.; Larson, D.R.; Van Wijnen, A.J.; Lewallen, D.G. Diabetes Mellitus and Hyperglycemia and the Risk of Aseptic Loosening in Total Joint Arthroplasty. J. Arthroplast. 2017, 32, S251-S253. [CrossRef] [PubMed]

52. Moon, J.K.; Jung, J.W.; Kim, Y.; Yang, J.H.; Park, Y.S.; Kim, Y.H. Acetabular cup migration after primary cementless total hip arthroplasty in rheumatoid arthritis and its influencing factors: A comparative study with osteoarthritic hip. Int. Orthop. 2020, 44, 1047-1053. [CrossRef] [PubMed]

53. Böhler, C.; Weimann, P.; Alasti, F.; Smolen, J.S.; Windhager, R.; Aletaha, D. Rheumatoid arthritis disease activity and the risk of aseptic arthroplasty loosening. Semin. Arthritis Rheum. 2020, 50, 245-251. [CrossRef] [PubMed]

54. Craiovan, B.; Woerner, M.; Winkler, S.; Springorum, H.R.; Grifka, J.; Renkawitz, T.; Keshmiri, A. Decreased femoral periprosthetic bone mineral density: A comparative study using DXA in patients after cementless total hip arthroplasty with osteonecrosis of the femoral head versus primary osteoarthritis. Arch. Orthop. Trauma Surg. 2016, 136, 709-713. [CrossRef] [PubMed]

55. Di Martino, A.; Castagnini, F.; Stefanini, N.; Bordini, B.; Geraci, G.; Pilla, F.; Traina, F.; Faldini, C. Survival rates and reasons for revision of different stem designs in total hip arthroplasty for developmental dysplasia: A regional registry study. J. Orthop. Traumatol. 2021, 22, 29. [CrossRef]

56. Gu, A.; Agarwal, A.R.; Fassihi, S.C.; Pollard, T.G.; Stoll, W.T.; Campbell, J.C.; Golladay, G.J.; Thakkar, S.C. Impact of sickle cell disease on postoperative outcomes following total hip arthroplasty. Hip Int. 2021, 11207000211052224. [CrossRef]

57. Strauss, A.C.; Rommelspacher, Y.; Nouri, B.; Bornemann, R.; Wimmer, M.D.; Oldenburg, J.; Pennekamp, P.H.; Schmolders, J. Long-term outcome of total hip arthroplasty in patients with haemophilia. Haemophilia 2017, 23, 129-134. [CrossRef]

58. Fontalis, A.; Kenanidis, E.; Bennett-Brown, K.; Tsiridis, E. Clinical outcomes in elective total hip arthroplasty in Parkinson's disease: A systematic review of the literature. EFORT Open Rev. 2020, 5, 856-865. [CrossRef]

59. Onochie, E.; Kayani, B.; Dawson-Bowling, S.; Millington, S.; Achan, P.; Hanna, S. Total hip arthroplasty in patients with chronic liver disease: A systematic review. SICOT J. 2019, 5, 40. [CrossRef]

60. Lieu, D.; Harris, I.A.; Naylor, J.M.; Mittal, R. Review article: Total hip replacement in haemodialysis or renal transplant patients. J. Orthop. Surg. 2014, 22, 393-398. [CrossRef]

61. Ofa, S.A.; Lupica, G.M.; Lee, O.C.; Sherman, W.F. Complications following total hip arthroplasty and hemiarthroplasty for femoral neck fractures in patients with a history of lumbar spinal fusion. Arch. Orthop. Trauma Surg. 2021, 1-11. [CrossRef] [PubMed]

62. Lemme, N.J.; Veeramani, A.; Yang, D.S.; Tabaddor, R.R.; Daniels, A.H.; Cohen, E.M. Total Hip Arthroplasty After Hip Arthroscopy Has Increased Complications and Revision Risk. J. Arthroplast. 2021, 36, 3922-3927.e2. [CrossRef] [PubMed]

63. Kapadia, B.H.; Issa, K.; Pivec, R.; Bonutti, P.M.; Mont, M.A. Tobacco use may be associated with increased revision and complication rates following total hip arthroplasty. J. Arthroplast. 2014, 29, 777-780. [CrossRef] [PubMed]

64. Myers, K.; Hajek, P.; Hinds, C.; McRobbie, H. Stopping Smoking Shortly Before Surgery and Postoperative Complications: A Systematic Review and Meta-analysis. Arch. Intern. Med. 2011, 171, 983-989. [CrossRef] [PubMed]

65. Cherian, J.J.; Jauregui, J.J.; Banerjee, S.; Pierce, T.; Mont, M.A. What Host Factors Affect Aseptic Loosening After THA and TKA? Clin. Orthop. Rel. Res. 2015, 473, 2700-2709. [CrossRef]

66. Nyström, A.; Kiritopoulos, D.; Ullmark, G.; Sörensen, J.; Petrén-Mallmin, M.; Milbrink, J.; Hailer, N.P.; Mallmin, H. Denosumab Prevents Early Periprosthetic Bone Loss After Uncemented Total Hip Arthroplasty: Results from a Randomized PlaceboControlled Clinical Trial. J. Bone Min. Res. 2020, 35, 239-247. [CrossRef]

67. Ro, D.H.; Jin, H.; Park, J.Y.; Lee, M.C.; Won, S.; Han, H.S. The use of bisphosphonates after joint arthroplasty is associated with lower implant revision rate. Knee Surg. Sports Traumatol. Arthrosc. 2019, 27, 2082-2089. [CrossRef]

68. Prieto-Alhambra, D.; Lalmohamed, A.; Abrahamsen, B.; Arden, N.K.; De Boer, A.; Vestergaard, P.; De Vries, F. Oral bisphosphonate use and total knee/hip implant survival: Validation of results in an external population-based cohort. Arthritis Rheumatol. 2014, 66, 3233-3240. [CrossRef]

69. Muratore, M.; Quarta, E.; Quarta, L.; Calcagnile, F.; Grimaldi, A.; Orgiani, M.A.; Marsilio, A.; Rollo, G. Ibandronate and cementless total hip arthroplasty: Densitometric measurement of periprosthetic bone mass and new therapeutic approach to the prevention of aseptic loosening. Clin. Cases Min. Bone Metab. 2012, 9, 50-55.

70. Zhao, X.; Hu, D.; Qin, J.; Mohanan, R.; Chen, L. Effect of bisphosphonates in preventing femoral periprosthetic bone resorption after primary cementless total hip arthroplasty: A meta-analysis. J. Orthop. Surg. Res. 2015, 10, 65. [CrossRef] 
71. Malahias, M.A.; Loucas, R.; Loucas, M.; Denti, M.; Sculco, P.K.; Greenberg, A. Preoperative Opioid Use Is Associated With Higher Revision Rates in Total Joint Arthroplasty: A Systematic Review. J. Arthroplast. 2021, 36, 3814-3821. [CrossRef] [PubMed]

72. Sorial, A.K.; Anjum, S.A.; Cook, M.J.; Board, T.N.; O'Neill, T.W. Statins, bone biology and revision arthroplasty: Review of clinical and experimental evidence. Adv. Musculoskelet. Dis. 2020, 12, 1759720X20966229. [CrossRef] [PubMed]

73. Vallés, G.; Pérez, C.; Boré, A.; Martín-Saavedra, F.; Saldaña, L.; Vilaboa, N. Simvastatin prevents the induction of interleukin-6 gene expression by titanium particles in human osteoblastic cells. Acta Biomater. 2014, 9, 4916-4925. [CrossRef] [PubMed]

74. Lübbeke, A.; Garavaglia, G.; Rothman, K.J.; Bonvin, A.; Roussos, C.; Miozzari, H.; Hoffmeyer, P. Statins may reduce femoral osteolysis in patients with total Hip arthroplasty. J. Orthop. Res. 2013, 31, 814-820. [CrossRef] [PubMed]

75. De Soto, P.C.-M.; Tamimi-Mariño, I.; Bautista-Enrique, D.; Bravo-Zurita, M.J.; Cáceres, A.G.; Tamimi, F.; Dawid-Milner, M.S. Use of beta-blockers and risk of aseptic loosening in total hip and knee arthroplasty: A nested case-Control study. J. Musculoskelet. Neuronal. Interact. 2019, 19, 104-111.

76. Wang, Z.; Xue, K.; Bai, M.; Deng, Z.; Gan, J.; Zhou, G.; Qian, H.; Bao, N.; Zhao, J. Probiotics protect mice from CoCrMo particles-induced osteolysis. Int. J. Nanomed. 2017, 12, 5387-5397. [CrossRef]

77. Qian, Y.; Zhang, X.-L.; Jiang, Y.; Zeng, B.-F.; Wang, Q.; Chen, Y.; Shen, H.; Wang, Q. Alendronate stimulates osteoprotegerin expression in fibroblasts from periprosthetic membrane. Hip Int. 2015, 25, 581-584. [CrossRef]

78. Duan, J.; Hu, X.; Li, T.; Wu, G.; Dou, P.; Ouyang, Z. Cimifugin Suppresses NF-кB Signaling to Prevent Osteoclastogenesis and Periprosthetic Osteolysis. Front. Pharm. 2021, 12, 724256. [CrossRef]

79. Yang, C.; Liu, W.; Zhang, X.; Zeng, B.; Qian, Y. Naringin increases osteoprotegerin expression in fibroblasts from periprosthetic membrane by the Wnt/ $\beta$-catenin signaling pathway. J. Orthop. Surg. Res. 2020, 15, 600. [CrossRef]

80. Tian, Y.; Terkawi, M.A.; Onodera, T.; Alhasan, H.; Matsumae, G.; Takahashi, D. Blockade of XCL1/Lymphotactin Ameliorates Severity of Periprosthetic Osteolysis Triggered by Polyethylene-Particles. Front. Immunol. 2020, 11, 1720. [CrossRef]

81. Ma, H.; Zhang, Q.; Shi, J.; Gao, Y.; Sun, C.; Zhang, W. Enalapril inhibits inflammatory osteolysis induced by wear debris in a mouse model. J. Int. Med. Res. 2020, 48, 300060520931612. [CrossRef] [PubMed]

82. An, S.; Han, F.; Hu, Y.; Liu, Y.; Li, J.; Wang, L. Curcumin Inhibits Polyethylene-Induced Osteolysis via Repressing NF- $\kappa B$ Signaling Pathway Activation. Cell Physiol. Biochem. 2018, 50, 1100-1112. [CrossRef]

83. Qin, C.Q.; Huang, D.S.; Zhang, C.; Song, B.; Huang, J.B.; Ding, Y. Lentivirus-mediated short hairpin RNA interference targeting TNF-alpha in macrophages inhibits particle-induced inflammation and osteolysis in vitro and in vivo. BMC Musculoskelet. Disord. 2016, 17, 431. [CrossRef] [PubMed]

84. Zhao, S.; Sun, Y.; Li, X.; Wang, J.; Yan, L.; Zhang, Z.; Wang, D.; Dai, J.; He, J.; Wang, S. Scutellarin inhibits RANKL-mediated osteoclastogenesis and titanium particle-induced osteolysis via suppression of NF- $\mathrm{B}$ and MAPK signaling pathway. Int. Immunopharmacol. 2016, 40, 458-465. [CrossRef] [PubMed]

85. Xu, Y.; Sang, W.; Zhong, Y.; Xue, S.; Yang, M.; Wang, C.; Lu, H.; Huan, R.; Mao, X.; Zhu, L.; et al. CoCrMo-Nanoparticles induced peri-implant osteolysis by promoting osteoblast ferroptosis via regulating Nrf2-ARE signalling pathway. Cell Prolif. 2021, 54, e13142. [CrossRef]

86. Zhang, Y.C.; Xiao, J.H.; Deng, S.J.; Yi, G.L. IRAK-4 in macrophages contributes to inflammatory osteolysis of wear particles around loosened hip implants. Innate Immun. 2021, 27, 470-482. [CrossRef] [PubMed]

87. Vasconcellos, L.M.; Leite, D.O.; Oliveira, F.N.; Carvalho, Y.R.; Cairo, C.A. Evaluation of bone ingrowth into porous titanium implant: Histomorphometric analysis in rabbits. Braz Oral. Res. 2010, 24, 399-405. [CrossRef]

88. Fender, D.; van der Meulen, H.P.; Gregg, P.J. Relationship between outcome and annual surgical experience for the Charnley total hip replacement. J. Bone Jt. Surg. 2003, 85, 187-190. [CrossRef]

89. Vermesan, D.; Prejbeanu, R.; Haragus, H.; Ahmadi, M.; Damian, G. Metallosis during partial component hip revision arthroplasty. Rev. Chim. 2021, 63, 953. 